\title{
THE RENAL REGULATION OF ACID-BASE BALANCE IN MAN. III. THE REABSORPTION AND EXCRETION OF BICARBONATE ${ }^{1}$
}

\author{
By R. F. PITTS, J. L. AYER, ANd W. A. SCHIESS \\ WITH THE TECHNICAL ASSISTANCE OF PHYLLIS MINER \\ (From the Department of Physiology, Syracuse University College of Medicine, Syracuse, N. Y.)
}

(Received for publication January 26, 1948)

In the normal individual the concentration of bicarbonate in the extracellular fluid is maintained within limits of 24 and $28 \mathrm{mM}$ per liter despite wide variations in the intake of acid and base forming foodstuffs. Stabilization of level depends on continuously operative renal mechanisms, for although carbonic acid is continously available, no large reserve depots of base exist upon which the body may draw when circulating stores are depleted, or to which the body may consign an excess in times of abundance. The renal problem of regulating the concentration of bicarbonate may be outlined in the following terms: 1 , conservation of those stores which normally enter the renal tubules in the glomerular filtrate; 2 , excretion of any excess present in the body; and 3, conversion of the salts of fixed acids into bicarbonate to replenish depleted body stores.

These aspects of regulation have been studied in normal human subjects at plasma bicarbonate levels ranging from 13 to $39 \mathrm{mM}$ per liter. It has been observed at plasma concentrations below $24 \mathrm{mM}$ per liter that essentially all of the filtered bicarbonate is reabsorbed; negligible quantities are lost in the urine. Above $28 \mathrm{mM}$ per liter a relatively constant quantity is reabsorbed, amounting on an average to $2.8 \mathrm{mM}$ per $100 \mathrm{ml}$. of glomerular filtrate; any excess present in the filtrate is excreted. These properties of the reabsorptive mechanism would in themselves assure stabilization of plasma level were there no continuous drain on bicarbonate stores for purposes of neutralizing fixed metabolic acid. Because such a drain exists in the individual maintained on the usual acid ash diet, the renal tubules must split neutral salts of the glomerular filtrate, restoring the fixed base to the body as bicarbonate, and eliminating the unwanted anions either as free titratable acid or in combination with ammonia.

1 Aided by grants from the United States Public Health Service and the John and Mary R. Markle Foundation.
Within limits these processes of replenishment proceed at rates proportional to the degree of depletion of the alkali reserves. The data upon which these findings are based are reported below.

\section{METHODS}

Fourteen experiments were performed on three healthy male subjects in the post-absorptive state. Adequate hydration was assured by the ingestion of two to four glasses of water at the start of each experiment. In some experiments plasma bicarbonate was reduced by the ingestion of 5 to $20 \mathrm{gms}$. of ammonium chloride on the preceding day. In all experiments plasma bicarbonate was elevated by the intravenous infusion of 1.5 to 3.0 per cent sodium bicarbonate at rates of 5 to $13 \mathrm{ml}$. per min. The thiosulfate clearance was used as a measure of glomerular filtration rate $(1,2)$.

Urine was collected with special precautions to avoid loss of carbon dioxide. One subject, who could empty the bladder completely of even small volumes of urine, voided into a funnel connected with a rubber tube dipping beneath oil. A close fit between funnel and glans minimized exposure of the urine to air. The other two subjects were catheterized and the catheter was extended under oil by attaching to it a length of rubber tubing. The urine was permitted to drain continuously through the catheter and at the end of the collection period the bladder was emptied by voluntary effort and abdominal compression. The customary procedure of washing out the bladder and introducing air at the end of each urine collection was avoided because of the error it causes in the determination of urinary carbon dioxide tension. Although more constant clearances were obtained in the subject who voided spontaneously, the similarity of carbon dioxide tensions in urine samples collected by the two methods, as well as the stability of tension for some six to eight hours after collection, indicated that both methods adequately protected against carbon dioxide loss. Arterialized venous blood was drawn and analyzed by methods described in a previous communication (3).

\section{RESULTS}

The reabsorption and excretion of bicarbonate as a function of plasma concentration

Two illustrative experiments on a single subject are presented in Table $I$; the first two clear- 
R. F. PITTS, J. L. AYER, AND W. A. SCHIESS

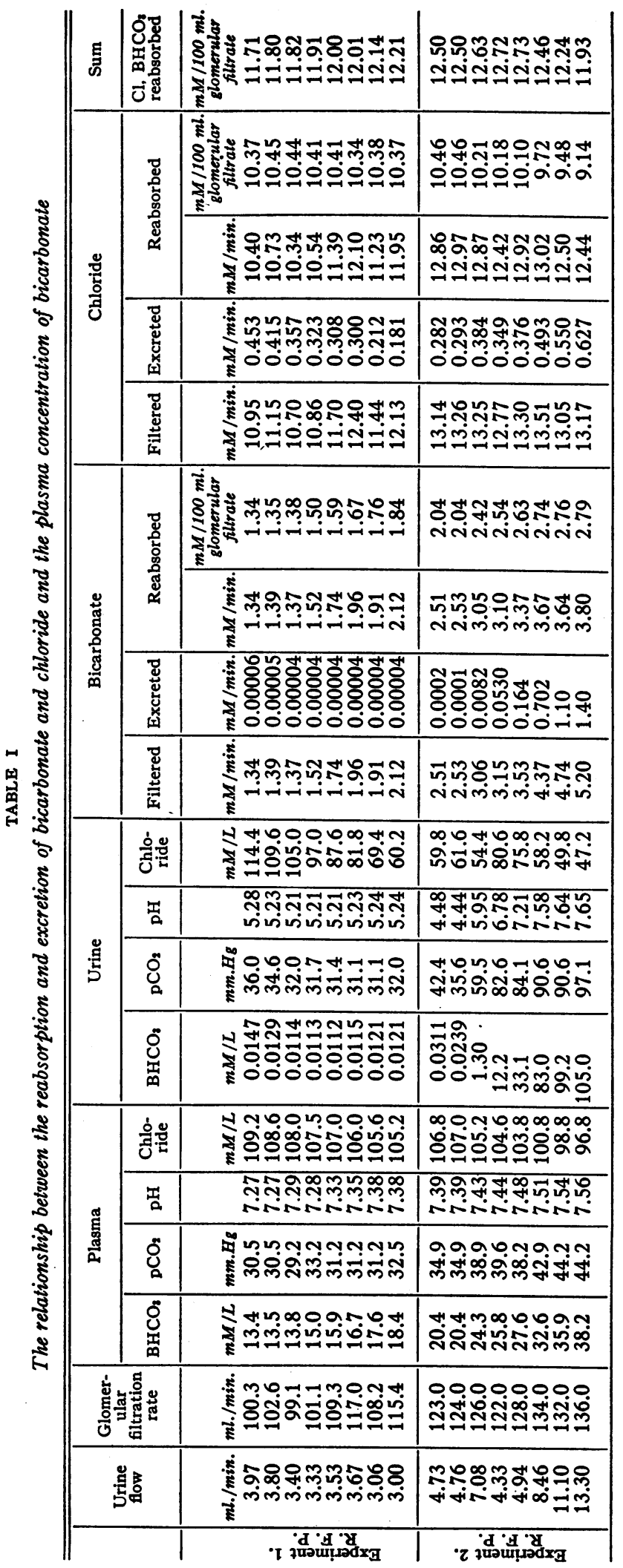


ance periods of each experiment constitute control observations made prior to the infusion of bicarbonate. Sufficient ammonium chloride had been ingested on the day preceding Experiment 1 to reduce the plasma bicarbonate concentration to $13.4 \mathrm{mM}$ per liter, $\mathrm{pH}$ to 7.27 , and partial pressure of carbon dioxide to $30.5 \mathrm{~mm}$. $\mathrm{Hg}$ in the initial two periods. The urine was acid in reaction and contained negligible quantities of bicarbonate. The quantity of bicarbonate filtered each minute was calculated by multiplying the plasma concentration, expressed in $\mathrm{mM}$ per $\mathrm{ml}$., by the glomerular filtration rate in $\mathrm{ml}$. per min. The quantity excreted was calculated by multiplying the urine concentration, expressed in $\mathrm{mM}$ per $\mathrm{ml}$., by the rate of urine flow in $\mathrm{ml}$. per min. The quantity reabsorbed is equal to the difference between the quantities filtered and excreted. It is evident that under conditions of moderately severe acidosis over 99.99 per cent of the filtered bicarbonate was reabsorbed; only a negligible trace was excreted.

Following the control periods of Experiment 1, the plasma concentration of bicarbonate was gradually raised from 13.5 to $18.4 \mathrm{mM}$ per liter by the infusion of bicarbonate, the reaction of the plasma returning to a normal value, namely $\mathrm{pH}$ 7.38. In consequence of the increase in plasma concentration and the increase in filtration rate, the quantity of bicarbonate delivered into the renal tubules rose from 1.34 to $2.12 \mathrm{mM}$ per min. Reabsorption of the filtered bicarbonate was essentially complete throughout this range. Likewise in Experiment 2 at a somewhat higher control level, reabsorption was equally complete. However, as the plasma level was raised to or above $25.8 \mathrm{mM}$ per liter, the renal tubules failed to reabsorb all of the bicarbonate presented to them, and significant quantities appeared in the urine.

It is apparent from the two experiments presented in Table $I$ that the rate of reabsorption of bicarbonate increased in direct proportion to the increase in plasma concentration; i.e., reabsorption increased from 1.34 to $3.80 \mathrm{mM}$ per min. as plasma concentration rose from 13.4 to $38.2 \mathrm{mM}$ per liter. However, there occurred coincidentally an increase in glomerular filtration rate, and since previous work on the dog (3) has shown that the tubular capacity to reabsorb bicarbonate at any given plasma level varies in proportion to filtration rate, the data were calculated in terms of $\mathrm{mM}$ reabsorbed per $100 \mathrm{ml}$. of glomerular filtrate. It is

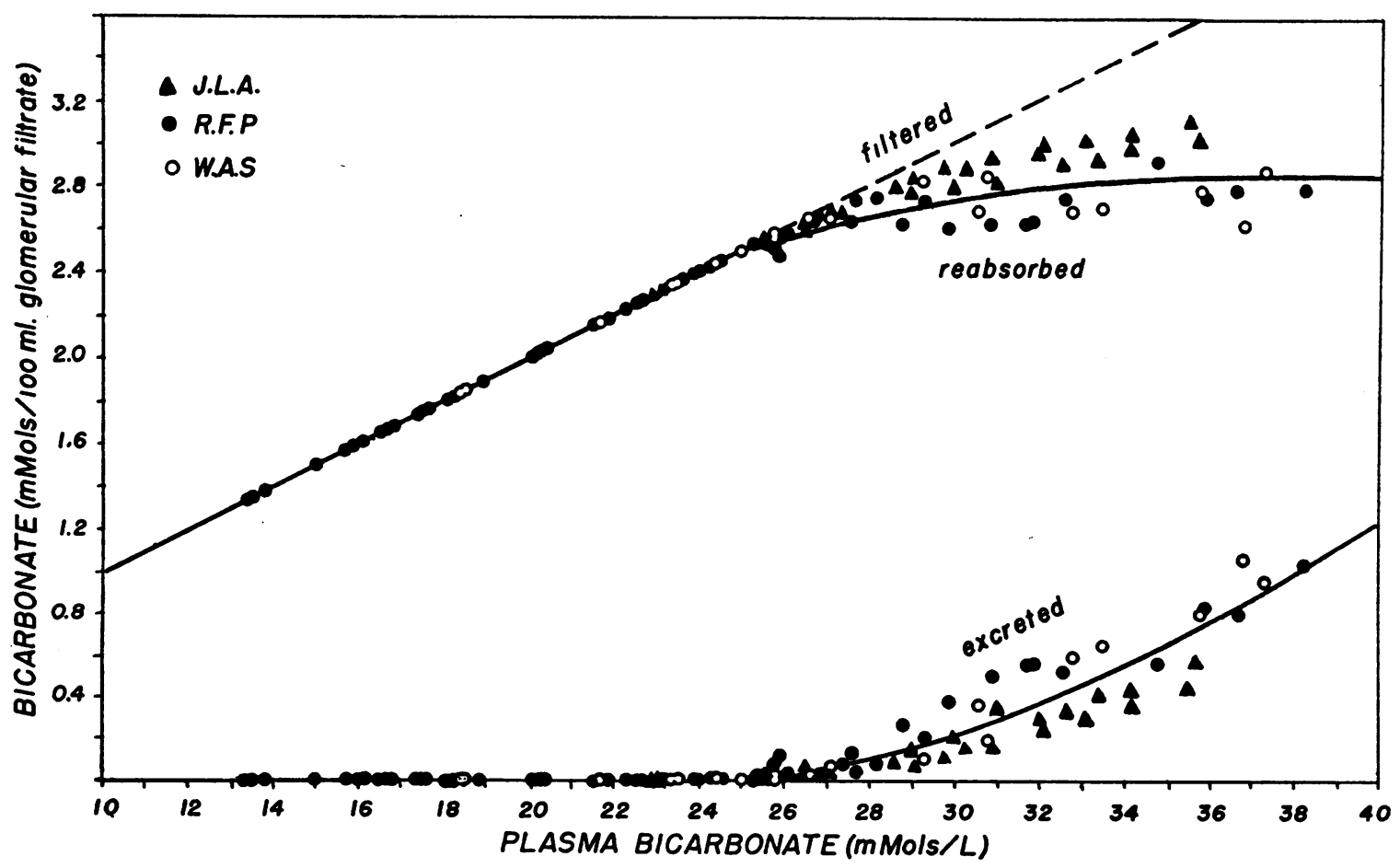

Fig. 1. The Reabsorption and Excretion of Bicarbonate as a Function of Plasma Levei. 
evident from Table I that bicarbonate reabsorption expressed in this fashion increased with plasma concentration up to a plasma level of 27.6 $\mathrm{mM}$ per liter. From 27.6 to $38.2 \mathrm{mM}$ per liter reabsorption was essentially constant, varying only from 2.63 to $2.79 \mathrm{mM}$ per $100 \mathrm{ml}$. of filtrate.

In Figure 1 are presented the massed data derived from 14 experiments on three subjects. The reabsorption and excretion of bicarbonate, expressed in $\mathrm{mM}$ per $100 \mathrm{ml}$. of glomerular filtrate, are plotted against plasma bicarbonate concentration. It is evident that reabsorption of filtered bicarbonate was essentially complete at plasma levels below $24 \mathrm{mM}$ per liter. Above $28 \mathrm{mM}$ per liter gross excretion occurred, and reabsorption was limited to an average value of $2.8 \mathrm{mM}$ per $100 \mathrm{ml}$. of glomerular filtrate (varying within limits of
2.6 and $3.0 \mathrm{mM}$ ). Thus the renal plasma threshold $^{2}$ for bicarbonate in this series of experiments varied only within narrow limits of 25 to $27 \mathrm{mM}$ per liter. It must be emphasized that this threshold probably holds exactly only under our experimental conditions of polyuria, acutely elevated bicarbonate concentration, and otherwise normal plasma electrolyte pattern.

Interaction in the reabsorption of chloride and bicarbonate

The ingestion of ammonium chloride converts a portion of the circulating store of bicarbonate into chloride, the increase in the latter roughly equaling the decrease in the former. In diarrhea

${ }^{2}$ Renal threshold is used in the sense of that plasma concentration above which significant excretion occurs.

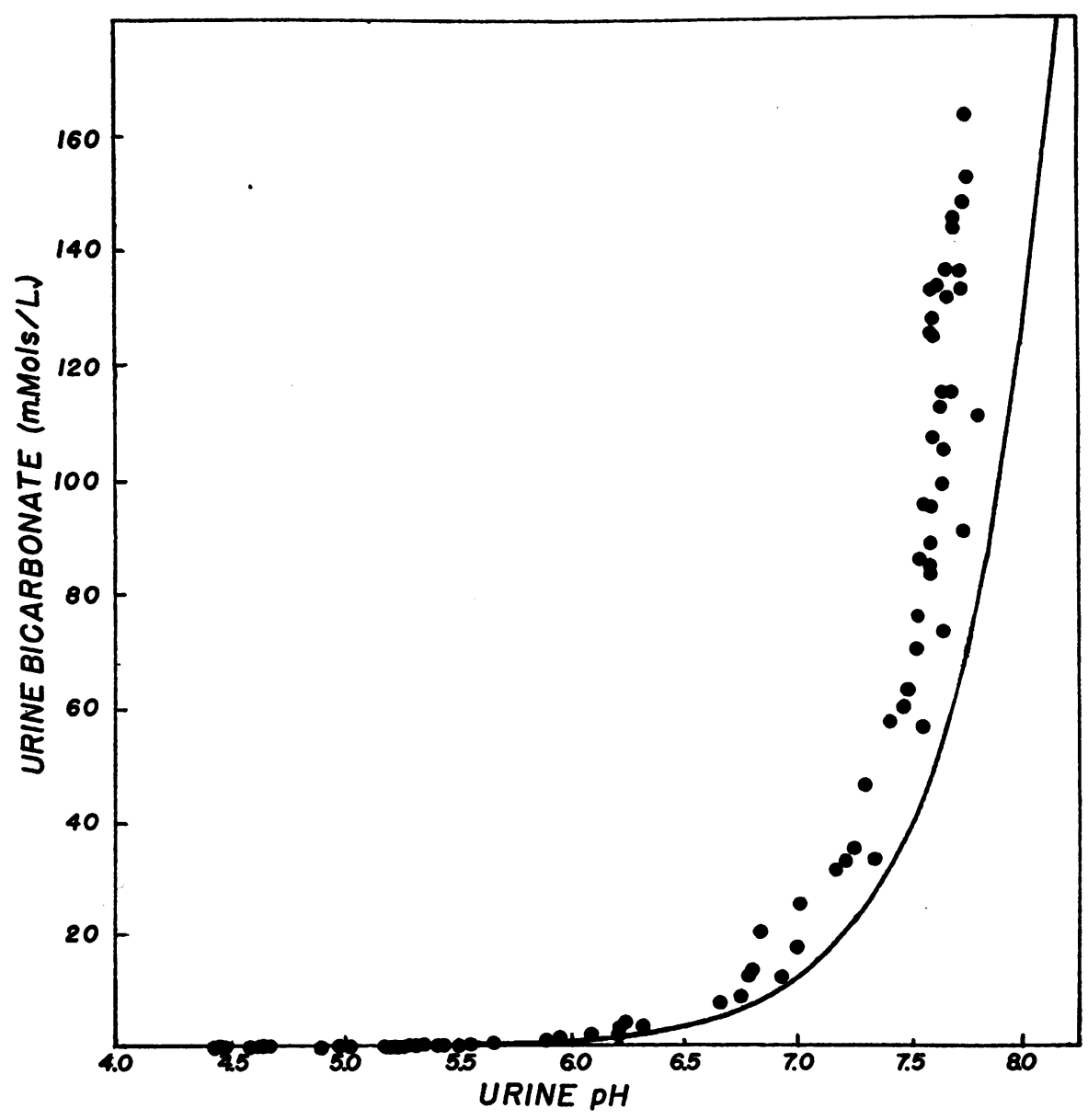

Fig. 2. The Relationship between Bicarbonate Concentration and pH in 82 Specimens of Urine so Collected as to Prevent loss of Carbon Dioxide

The smooth curve was calculated from the Henderson-Hasselbalch equation assuming a constant $\mathrm{pCO}_{2}$ of $50 \mathrm{~mm}$. $\mathrm{Hg}$. 

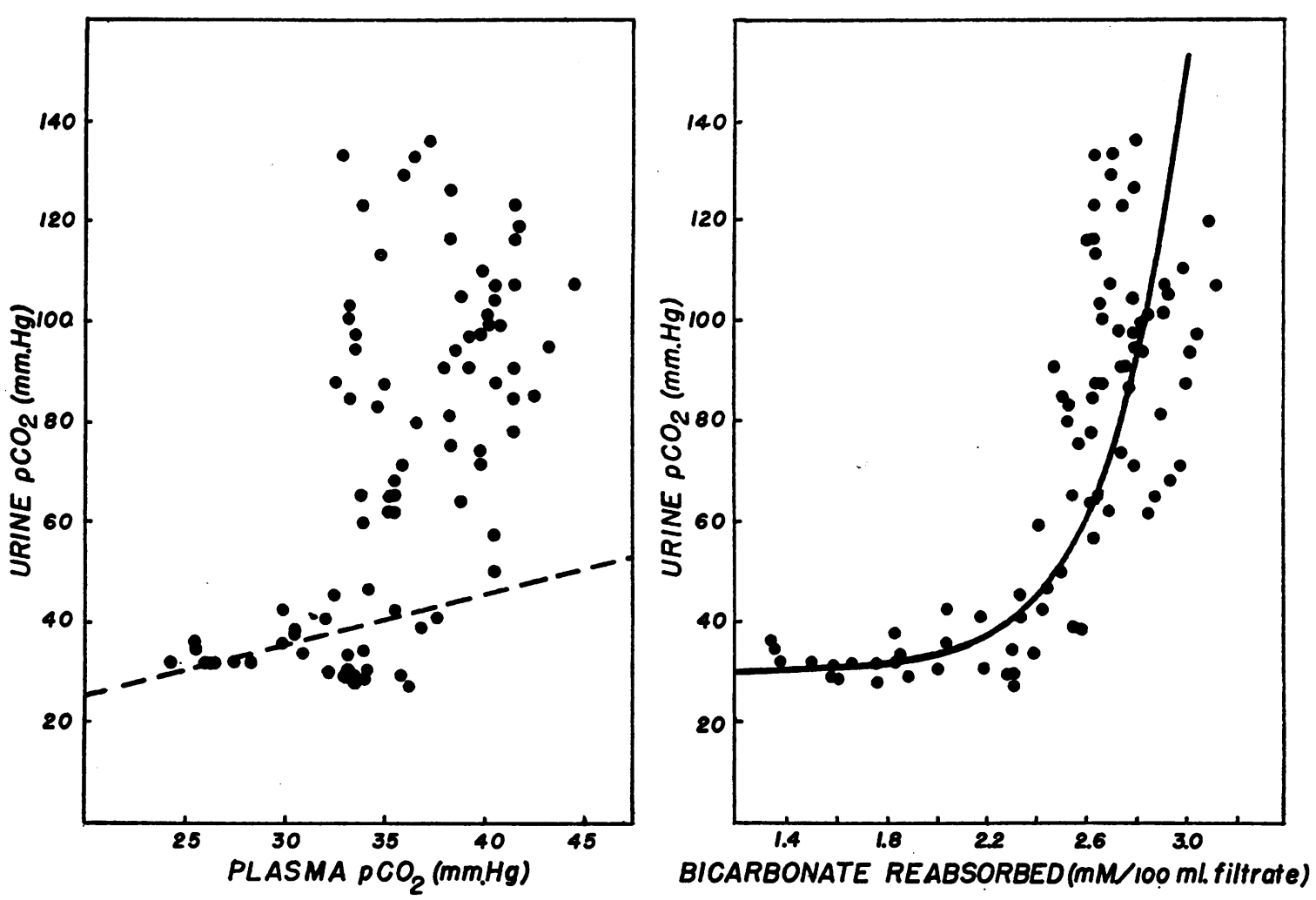

Fig. 3. Left: the Relationship between the $\mathrm{PCO}_{2}$ of the Urine and the pCO, of the Plasma Right: the Relationship between the PCO, of the Urine and the Reabsorption of Bicarbonate

a similar disturbance of electrolyte pattern results from the loss of alkaline intestinal secretions (4, 5). In contrast in pernicious vomiting, loss of chloride is attended by a compensatory elevation of plasma bicarbonate $(4,6,7)$. Thus there exists an inverse relationship between the plasma concentrations of chloride and bicarbonate, whereby the sum of the two is maintained relatively constant. Under conditions of stress, the kidney, failing to maintain the normal anion pattern, at least approximates maintenance of constant total anion (hence cation) concentration. As illustrated in Experiment 2 of Table I, this appears to result from compensatory changes in the quantities of chloride and bicarbonate reabsorbed, when one is presented to the renal tubules in excess. Thus $10.46 \mathrm{mM}$ of chloride were reabsorbed per $100 \mathrm{ml}$. of glomerular filtrate at a plasma bicarbonate concentration of $20.4 \mathrm{mM}$ per liter. As the bicarbonate level was raised the reabsorption of chloride fell and the excretion rose. The sum of chloride and bicarbonate reabsorbed, however, remained roughly constant.

\section{The acid-base equilibrium of the urine}

When an excess of base is liberated in the body in consequence of the metabolism of an alkaline ash diet, it is converted to bicarbonate and excreted in the urine. Gamble (8) and Marshall (9) have shown that the carbon dioxide tension of the urine roughly approximates that of the blood, hence large quantities of base bound as bicarbonate can be eliminated in urine of moderate alkalinity. As much as $220 \mathrm{mM}$ of bicarbonate can be excreted in a liter of urine of $\mathrm{pH}$ 8.0. In Figure 2, the concentration of bicarbonate in the urines from our 14 experiments are plotted against urine $\mathrm{pH}$. The reaction of the most acid urine was $\mathrm{pH} 4.44$, that of the most alkaline, $\mathrm{pH} 7.80$. The maximum concentration of bicarbonate was $164 \mathrm{mM}$ per liter, a figure which is relatively low because of the diuretic conditions in our experiments; the minimum concentration was $0.00001 \mathrm{mM}$ per liter. The smooth curve of Figure 2 was calculated from the Henderson-Hasselbalch equation assuming a urine $\mathrm{pCO}_{2}$ of $50 \mathrm{~mm}$. $\mathrm{Hg}$. It is evident that above 
$\mathrm{pH} 6.5$ the reaction of the urine is less alkaline than would be predicted from its content of bicarbonate. This deviation results from the fact, evident in Table $I$, that urines of high bicarbonate content have a higher $\mathrm{pCO}_{2}$ than that assumed in calculating the curve. As shown in Figure 3, carbon dioxide tensions as high as $136 \mathrm{~mm}$. $\mathrm{Hg}$ were observed in some urines of high bicarbonate content.

In Figure 3 the urinary partial pressure of carbon dioxide was plotted in two ways, on the left, against the simultaneously determined plasma partial pressure, and on the right, against the quantity of bicarbonate reabsorbed per $100 \mathrm{ml}$. of glomerular filtrate. It is evident from the lefthand graph that the $\mathrm{pCO}_{2}$ of the urine is with few exceptions equal to or greater than that of the plasma from which it was formed. Those points below the dashed line of equivalence may be low because of inaccuracies introduced by loss of carbon dioxide or because of variations of $\mathrm{pK}^{\prime}$ which would render the calculations inexact. The relationship, however, is less significant than that demonstrated in the righthand graph, which relates urinary $\mathrm{pCO}_{2}$ and bicarbonate reabsorption. It is evident that at values of reabsorption less than $2.0 \mathrm{mM}$ per $100 \mathrm{ml}$. of filtrate, $\mathrm{pCO}_{2}$ was relatively constant, at values greater than this it increased rapidly. For reasons which will be amplified subsequently, it is believed that in the process of distal tubular reabsorption of bicarbonate, carbonic acid is liberated in the tubular urine. Were it possible to plot urine $\mathrm{pCO}_{2}$ against distal rather than total bicarbonate reabsorption, a more exact correlation might be evident.

\section{The relation between titratable acid and ammonia excretion and alkali reserve}

Since the excretion of acid anions in combination with ammonia and as free titratable acid serves to replenish body stores of bicarbonate, the rates of both processes are determined in part by the extent of depletion of the alkali reserve (10). Base economy, which serves as a measure of the effective restoration of this reserve, is determined as the sum of the rates of ammonia and titratable acid excretion minus the rate of bicarbonate excretion (11). The contribution of each of these compo-

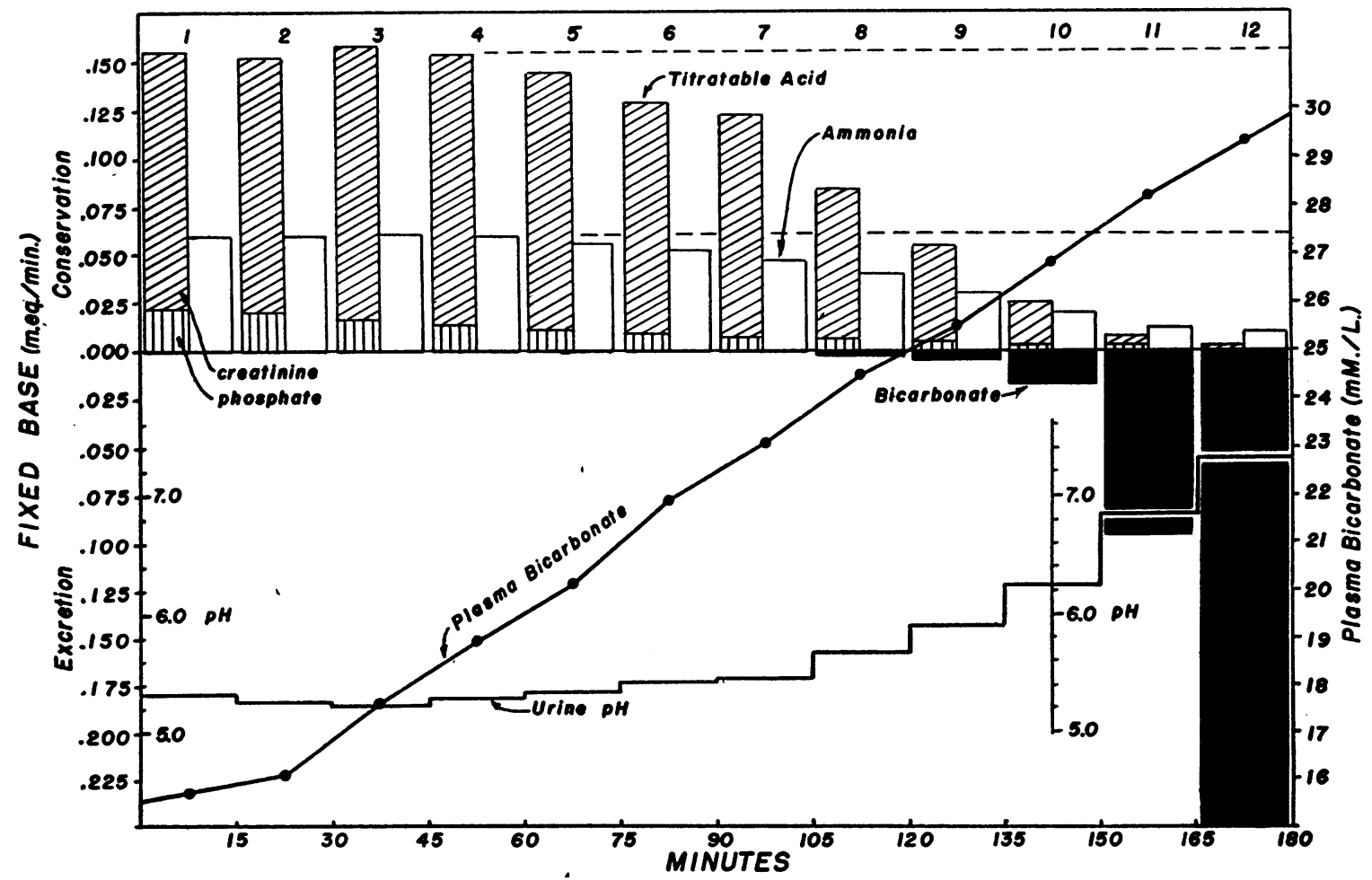

Fig. 4. The Relationship between Base Conservation (Ammonia and Titratable Acid Excretion), Base Excretion (as Bicarbonate), and Plasma Level of Bicarbonate 
nents to base economy was studied at a series of plasma bicarbonate levels. The results of such an experiment are presented in Figure 4. Since the rate of excretion of buffer substances by the fasted subject in ammonium chloride acidosis is low, creatinine was infused to increase the elimination of titratable acid to levels sufficient for accurate evaluation. Throughout the experiment the rate of excretion of creatinine was maintained at a constant high value. In Figure 4 titratable acid and ammonia elimination are plotted upward, bicarbonate elimination downward, to emphasize their opposite relations to base economy. The titratable acid ${ }^{3}$ indicated was largely exogenous creatinine, to a slight extent endogenous phosphate as noted on the graph.

During the initial two control periods of this experiment, at plasma bicarbonate levels of 15 to $16 \mathrm{mM}$ per liter, $0.150 \mathrm{mEq}$ of titratable acid and $0.060 \mathrm{mEq}$ of ammonia were excreted per minute. Base economy equalled the sum of these figures, for bicarbonate excretion was negligible. Sodium bicarbonate was then infused and the plasma concentration was raised as a linear function of time over a range of 16 to $30 \mathrm{mM}$ per liter. Acid and ammonia excretion remained at their initial high levels until the fifth period, when at a plasma bicarbonate level of $20 \mathrm{mM}$ per liter, the first perceptible reduction in these components of base economy was evident.

No significant excretion of bicarbonate occurred until the tenth period at a plasma concentration of $26.7 \mathrm{mM}$ per liter, although before this level was reached, titratable acid and ammonia excretion had declined to a fraction of their control values. Thus over the range of 20 to $26 \mathrm{mM}$ per liter the rates of excretion of acid and ammonia decreased in proportion to the increase in the rate of reabsorption of bicarbonate, in the absence of significant excretion of bicarbonate. We interpret this to mean that a type of competitive inhibition of acid and ammonia excretion results from increased reabsorption of bicarbonate. Since acid and ammonia are formed in the distal segment of the renal

8 Titratable acid values were calculated from the pH of the urine, collected in such fashion as to avoid loss of carbon dioxide, and the measured rates of excretion of creatinine and phosphate. They do not, therefore, include titratable acid contributed by dissolved carbon dioxide. tubules $(12,13)$ and since the final moiety of bicarbonate is reabsorbed from the tubular urine in this same segment (3), we incline to the view that interference occurs at this level. At plasma concentrations less than $20 \mathrm{mM}$ per liter the quantity of bicarbonate delivered into the distal segment is so small that little interference results, and urine of maximal acidity and ammonia content may be formed. However, other factors, especially the duration of the acidosis, affect the excretion of ammonia. Perhaps these factors are the uncontrolled variables which render certain mathematical relationships between base conservation and alkali reserve (14) inexact in some instances.

\section{DISCUSSION}

The properties of the renal mechanisms for the reabsorption of bicarbonate in normal man are such as to assure stabilization of plasma concentration at a level of 24 to $28 \mathrm{mM}$ per liter. At plasma concentrations less than $24 \mathrm{mM}$ per liter, essentially all of the bicarbonate delivered into the renal tubules in the glomerular filtrate is conserved, none is lost in the urine. Furthermore acid elimination and ammonia excretion are stimulated as the plasma bicarbonate level falls below $24 \mathrm{mM}$ per liter. Both processes serve to restore base to the body as bicarbonate and thus to rebuild depleted reserves. At plasma concentrations above $28 \mathrm{mM}$ per liter a relatively constant quantity of bicarbonate, namely, $2.8 \mathrm{mM}$ per $100 \mathrm{ml}$. of glomerular filtrate, is reabsorbed; the excess is excreted in the urine, and plasma concentration returns toward the normal value.

The nature of the tubular mechanisms accomplishing these ends cannot be completely defined at present but sufficient information exists to permit their partial characterization. It is evident that no less than two-thirds (15), and possibly as much as four-fifths or more (16) of the fluid filtered at the glomerulus is reabsorbed during its passage through the proximal segment of the renal tubule. According to Walker (15), the residual tubular fluid and hence the reabsorbate are essentially in osmotic equilibrium with the plasma. Only in the distal tubule does concentration or dilution of the tubular urine occur. Wesson (17) holds that electrolytes are actively reabsorbed in the proximal segment and that the removal of these and 
other osmotically active constituents from the tubular fluid creates a diffusion force which causes the return of water to the blood stream. Thus the composition of the residual tubular fluid varies in its course through the proximal segment owing to the progressive removal of its several valuable constituents and to the progressive concentration of its waste components, yet the osmotic pressure of this fluid remains nearly the same as that of the plasma, for the tubular epithelium is presumed to be freely permeable to water.

In the rat and guinea pig (15) and apparently in the dog as well (17), bicarbonate is reabsorbed relatively more rapidly than is water, chloride or sodium. Thus the concentration of bicarbonate in the proximal tubular fluid falls below, that of sodium remains nearly the same as, and that of chloride rises above its respective level in the glomerular filtrate. If the reabsorption of bicarbonate and chloride were the consequence of passive diffusion conditioned only by electrostatic forces and by the active transfer of sodium, one would expect chloride to be reabsorbed relatively more rapidly than bicarbonate, for the mobility of the hydrated chloride ion is greater than that of the hydrated bicarbonate ion." The preferential reabsorption of bicarbonate in the proximal tubule therefore suggests its active transport.

This active transport mechanism must be of such nature as to satisfy the following requirements. Ionic electroneutrality of the tubular fluid and reabsorbate must obviously be preserved. The capacity of the mechanism to transfer bicarbonate must be limited in some fashion, for as described above, all filtered bicarbonate in excess of $2.8 \mathrm{mM}$ per $100 \mathrm{ml}$. is excreted. However, transport capacity, although limited, is not fixed, for at any given plasma level the quantity of bicarbonate reabsorbed is linearly related to glomerular filtration rate (3). These latter two characteristics in reality apply to the overall reabsorption of bicarbonate, but since the major reabsorption of this ion species occurs in the proximal segment, they must be considered to be characteristics of the proximal mechanism. Any further description of the nature of this mechanism is impossible at the present state of our knowledge.

\footnotetext{
4 This statement is based on the specific conductivities of the two ion-species derived from the International Critical Tables.
}

From evidence presented previously (3) as well as that outlined above, the distal tubular mechanism for the reabsorption of bicarbonate would appear to be the same as that which converts urinary buffer salts into free titratable acid. This latter mechanism accomplishes the exchange of hydrogen ions, formed within the tubular cells, for fixed base bound by weak acid anions in the tubular urine. These acid anions are eliminated as titratable acid; the base is returned to the body as bicarbonate (18-20). A similar exchange of hydrogen ions for bicarbonate bound base would form carbonic acid in the tubular urine. Since carbonic anhydrase is absent from the tubular fluid, dehydration of carbonic acid to carbon dioxide would proceed slowly, and, providing any significant quantity of carbonic acid were formed, one would predict that the carbon dioxide tension of the bladder urine would exceed that of plasma.

As shown in the lefthand graph of Figure 3, the carbon dioxide tension of the urine equals or exceeds that of the plasma. As shown in the righthand one the greater the quantity of bicarbonate reabsorbed, the higher the carbon dioxide tension of the urine. We infer that at plasma concentrations less than $20 \mathrm{mM}$ per liter, the bulk of the bicarbonate is reabsorbed in the proximal segment, little is delivered into the distal segment to be absorbed by ion exchange. Accordingly the carbon dioxide tension of the urine is low and approximates that of the plasma. At higher plasma concentrations, proximal reabsorption is incomplete, and appreciable quantities of bicarbonate are delivered into the distal segment to undergo reabsorption by ion exchange. As total absorption exceeds $2.2 \mathrm{mM}$ per $100 \mathrm{ml}$. of filtrate, the distal contribution becomes appreciable, and the carbon dioxide tension of the urine rises rapidly to a value some three to four times that of the plasma.

The view of the identity of the distal ion exchange and bicarbonate absorption mechanisms is strengthened by the observation, illustrated in Figure 4, that there exists a type of competitive interference between bicarbonate reabsorption and titratable acid excretion, at least at plasma bicarbonate levels between 20 and $26 \mathrm{mM}$ per liter. At plasma levels below $20 \mathrm{mM}$ per liter no interference occurs for the bulk of the bicarbonate is absorbed in the proximal segment and little reaches the level of the distal ion exchange mechanism. 
At plasma levels above $20 \mathrm{mM}$ per liter bicarbonate reaches the distal segment in increasing quantities and bicarbonate bound base competes with base bound by fixed buffer acids in the exchange process. Accordingly, the excretion of titratable acid varies inversely with bicarbonate absorption over a range of plasma concentration of 20 and $26 \mathrm{mM}$ per liter. Above 26 to $28 \mathrm{mM}$ per liter frank excretion of bicarbonate occurs and titratable alkali is eliminated in the urine.

A third line of evidence favoring identity of the distal ion exchange and bicarbonate absorption mechanisms is derived from experiments on the dog described previously (3). Sulfanilamide blocks the excretion of titratable acid and reduces the reabsorption of bicarbonate. Presumably it inhibits the enzyme carbonic anhydrase which plays a role in the distal tubular exchange of hydrogen ions for base $(18,19)$. Bicarbonate reabsorption is only partially blocked by sulfanilamide; presumably it is the distal moiety, entering into the ion exchange mechanism, which is affected.

Although these experiments outline in a general way the relation between plasma concentration, reabsorption and excretion of bicarbonate, they throw no light on the means by which hyperventilation brings about increased bicarbonate excretion. Forced breathing, induced voluntarily or reflexly in consequence of anoxia, lowers the bicarbonate content of the blood, yet leads to the formation of alkaline urine (11). Obviously the capacity of the renal tubules to reabsorb bicarbonate must be reduced, but no evidence exists as to the nature or site of action of the stimulus which brings about this reduction. It is possible that changes in plasma $\mathrm{pH}$ may in some way yet to be defined exert a regulatory influence over bicarbonate reabsorption. It is well known that changes in plasma $\mathrm{pH}$ of considerable magnitude occur with hyperventilation.

\section{SUM MARY}

The renal reabsorption and excretion of bicarbonate have been studied in three normal subjects over a range of plasma concentration of 13 to $38 \mathrm{mM}$ per liter. At plasma levels below $24 \mathrm{mM}$ per liter essentially all of the bicarbonate entering the renal tubules in the glomerular filtrate is reabsorbed. Above $28 \mathrm{mM}$ per liter a relatively con- stant quantity, averaging $2.8 \mathrm{mM}$ per $100 \mathrm{ml}$. of glomerular filtrate, is reabsorbed; the excess is eliminated in the urine. Under the conditions of our experiments the renal threshold is 25 to 27 $\mathrm{mM}$ of bicarbonate per liter of plasma. Evidence is presented that bicarbonate is reabsorbed by two dissimilar mechanisms, a proximal and a distal one. The latter mechanism appears to be the same as that which converts buffer salts of the tubular urine into free titratable acid. The properties of the proximal and distal tubular reabsorptive mechanisms of man are similar to those previously described in the dog.

\section{BIBLIOGRAPHY}

1. Newman, E. V., Gilman, A., and Philips, F. S., The renal clearance of thiosulfate in man. Bull. Johns Hopkins Hosp., 1946, 79, 229.

2. Pitts, R. F., and Lotspeich, W. D., Use of thiosulfate clearance as a measure of glomerular filtration rate in acidotic dogs. Proc. Soc. Exper. Biol. \& Med., 1947, 64, 224.

3. Pitts, R. F., and Lotspeich, W. D., Bicarbonate and the renal regulation of acid base balance. Am. J. Physiol., 1946, 147, 138.

4. Hartmann, A. F., Chemical changes in the body as a result of certain diseases. I. The effect of diarrhea, vomiting, dehydration and oliguria on the acid-base balance of the plasma of infants with mastoiditis. Am. J. Dis. Child., 1928, 35, 557.

5. Hamilton, B., Kajdi, L., and Meeker, D., The acidosis of acute diarrhea in infancy. Am. J. Dis. Child., 1929, 38, 314.

6. MacCallum, W. G., Lintz, J., Vermilye, H. N., Leggett, T. H., and Boas, E., The effect of pyloric obstruction in relation to gastric tetany. Bull. Johns Hopkins Hosp., 1920, 31, 1.

7. Hastings, A. B., Murray, C. D., and Murray, H. A., Jr., Certain chemical changes in the blood after pyloric obstruction in dogs. J. Biol. Chem., 1921, 46, 223.

8. Gamble, J. L., Carbonic acid and bicarbonate in urine. J. Biol. Chem., 1922, 51, 295.

9. Marshall, E. K., Jr., The effect of loss of carbon dioxide on the hydrogen ion concentration of urine. J. Biol. Chem., 1922, 51, 3.

10. Gamble, J. L., Chemical anatomy, physiology and pathology of extracellular fluid. A lecture syllabus. Department of Pediatrics, The Harvard Medical School, 1941.

11. Peters, J. P., and Van Slyke, D. D., Quantitative Clinical Chemistry, Vol. I, Interpretations. Williams and Wilkins Co., Baltimore, 1931.

12. Montgomery, H., and Pierce, J. A., The site of acidification of the urine within the renal tubule in amphibia. Am. J. Physiol., 1937, 118, 144. 
13. Walker, A. M., Ammonia formation in the amphibian kidney. Am. J. Physiol., 1940, 131, 187.

14. Fitz, R., and Van Slyke, D. D., Studies in acidosis. IV. The relationship between alkaline reserve and acid excretion. J. Biol. Chem., 1917, 30, 389.

15. Walker, A. M., Bott, P. A., Oliver, J., and MacDowell, M., The collection and analysis of fluid from single nephrons of the mammalian kidney. Am. J. Physiol., 1941, 134, 580.

16. Smith, H. W., Physiology of the Kidney. Oxford Press, New York, 1937.
17. Wesson, L. G., Anslow, W. P., Jr., and Smith, H. W., The renal excretion of strong electrolytes. Federation Proc., 1948, 7, 132.

18. Pitts, R. F., and Alexander, R. S., The nature of the renal tubular mechanism for acidifying the urine. Am. J. Physiol., 1945, 144, 239.

19. Pitts, R. F., Lotspeich, W. D., Schiess, W. A., and Ayer, J. L., The renal regulation of acid-base balance in man. $I$. The nature of the mechanism for acidifying the urine. J. Clin. Invest., 1948, 27, 48.

20. Pitts, R. F., Renal excretion of acid. Federation Proc., 1948, 7, 418. 